Arq. Bras. Med. Vet. Zootec., v.69, n.3, p.704-710, 2017

\title{
Metabolizabilidade da energia de farinhas mistas contendo silagem de peixes para frangos de corte
}

\author{
[Energy metabolizability of mixed flour containing fish silage for broiler chicken] \\ G.T.G. Cunha ${ }^{1}$, M.C.M.M. Ludke ${ }^{1 *}$, J.V. Ludke ${ }^{2,}$ C.B.V. Rabello ${ }^{1}$, J.S. Barros ${ }^{1}$, J.S. Santos ${ }^{1}$ \\ ${ }^{1}$ Universidade Federal Rural de Pernambuco - Recife, PE \\ ${ }^{2}$ Embrapa Suínos e Aves - Concórdia, SC
}

\begin{abstract}
RESUMO
Objetivou-se com este trabalho determinar o valor nutricional e os valores de energia metabolizável aparente (EMA) e EMA corrigida para o balanço de nitrogênio (EMAn) de quatro farinhas mistas contendo silagem de resíduo de filetagem de tilápia para frangos de corte do tipo crescimento lento com 28 a 38 dias de idade. Analisou-se a composição físico-química das silagens e, em seguida, realizou-se um ensaio de metabolismo pelo método de coleta total de excretas com 180 pintos machos da linhagem Vermelho Pesadão Francês, distribuídos em um delineamento inteiramente ao acaso, com cinco tratamentos, seis repetições e seis aves por unidade experimental. Os tratamentos consistiram de uma ração referência (RR) e quatro dietas teste compostas de $70 \%$ da (RR), com a inclusão de $30 \%$ de farinha mista contendo silagem de peixes produzida com o farelo de algaroba (SFA), com a farinha de varredura de mandioca (SFVM), com o farelo de milho (SFM) e com a casca da mandioca (SCM). Os valores para composição físico-química das SFA, SFVM, SFM, SCM foram de 20,63, 20,76, 21,99 e 14,54\% de proteína bruta; $17,04,23,22,21,97$ e $20,27 \%$ de extrato etéreo; $7,53,7,79,8,65$ e $8,83 \%$ de matéria mineral; $23,07,10,55,16,81$ e $12,34 \%$ de fibra bruta; $1,79,2,30,1,57$ e $2,72 \%$ de cálcio; $1,12,1,72,1,45$ e 1,94\% de fósforo; 532, 528, 598 e 508 densidade, $\mathrm{g} / \mathrm{L} ; 4,5,4,0,4,4$ e 4,4 de $\mathrm{pH}$. Quanto aos valores de EMA e EMAn das farinhas mistas contendo silagem de peixes em base de matéria seca, foram, respectivamente, $3560 \mathrm{kcal} / \mathrm{kg}$ e $3402 \mathrm{kcal} / \mathrm{kg}$ para a SFA, $3574 \mathrm{kcal} / \mathrm{kg}$ e $3415 \mathrm{kcal} / \mathrm{kg}$ para a $S F V M$, $3570 \mathrm{kcal} / \mathrm{kg}$ e $3412 \mathrm{kcal} / \mathrm{kg}$ para a SFVM e $3571 \mathrm{kcal} / \mathrm{kg}$ e $3413 \mathrm{kcal} / \mathrm{kg}$ para a SCM, com a SFA apresentando menor valor $(\mathrm{P}=0,01)$. Com base nos resultados, as silagens contendo restos de peixe podem ser utilizadas em dietas para frangos de corte.
\end{abstract}

Palavras-chave: alimento alternativo, aves, casca de mandioca, energia metabolizável, farelo de algaroba

\begin{abstract}
The objective of this study was to determine the nutritional value and the values of Apparent Metabolizable Energy (AME) and AME corrected for nitrogen balance (AMEn) of four mixed meals containing fish silage for slow growth type broiler chickens at 28-38 days of age. The physicochemical composition of the silage was analyzed and then a metabolism trial was performed using total excreta collection method with 180 male chicks of Red French Pesadão lineage distributed in a completely randomized design with five treatments and six replicates of six birds per experimental unit. Treatments consisted of a basal diet (RR) and four test diets containing 70\% (RR), with the inclusion of 30\% of mixed flour containing fish silage produced with mesquite meal (SFA) with flour of cassava meal (SFVM), with corn meal (SFM), and dehydrated cassava peel (SCM). The values for physico-chemical composition of the SFA, SFVM, SFM, SCM, were 20,63, 20.76, 21.99, and 14.54\% of crude protein; 17.04, 23.22, 21.97 and $20.27 \%$ of ethereal extract; $7.53,7.79,8.65$, and $8.83 \%$ of mineral matter; $23,07,10,55,16,81$, and $12,34 \%$ of crude fiber; $1.79,2.30,1.57$, and $2.72 \%$ of calcium; 1.12, 1.72, 1.45 , and $1.94 \%$ of phosphorus; 532, 528, 598, and 508 of density, $g$ / L; 4.5, 4.0, 4.4, and 4.4 of pH. As for AME and AMEn
\end{abstract}

Recebido em 19 de julho de 2016

Aceito em 31 de outubro de 2016

*Autor para correspondência (corresponding author)

E-mail: maria.mmarques@ufrpe.br 
of the flours containing fish silage on dry matter basis, values were of, respectively, $3560 \mathrm{kcal} / \mathrm{kg}$ and $3402 \mathrm{kcal} / \mathrm{kg}$ for the SFA, $3574 \mathrm{kcal} / \mathrm{kg}$ and $3415 \mathrm{kcal} / \mathrm{kg}$ for SFVM, $3570 \mathrm{kcal} / \mathrm{kg}$ and $3412 \mathrm{kcal} / \mathrm{kg}$ for SFVM, and $3571 \mathrm{kcal} / \mathrm{kg}$ and $3413 \mathrm{kcal} / \mathrm{kg}$ for SCM, with the SFA showing lowest value. Based on the results, silage containing fish waste can be used in diets for broilers.

Keywords: Alternative feed, birds, cassava peel, metabolizable energy, mesquite meal

\section{INTRODUÇÃO}

A avaliação de alimentos alternativos e seu uso na alimentação animal possibilitam a redução dos custos de produção e têm reflexos diretos na viabilidade do sistema produtivo avícola (Brum Jr. et al., 2007). Do ponto de vista financeiro, a ração participa com $70 \%$ do custo total e este custo é variável em função do preço do farelo de soja e do milho, componentes com parcelas significativas na composição da ração do frango. Dessa forma, quanto menor o custo por unidade de frango, maior a rentabilidade financeira.

Diversos subprodutos agroindustriais precisam ser estudados visando ao emprego em larga escala e à redução dos seus efeitos poluentes. Dentre eles, destaca-se a farinha de resíduos industriais de filetagem de tilápia (cabeça, espinhas, vísceras, gordura abdominal e barbatanas), que, segundo Richart et al. (2016), apresenta, em média, 95,28\% de matéria seca, $53,43 \%$ de proteína bruta, $16,82 \%$ de extrato etéreo, $23,42 \%$ de matéria mineral, $6,98 \%$ de cálcio e $3,52 \%$ de fósforo.

Segundo Borghesi (2004), a produção de silagem ácida de peixe é um processo simples, de baixo custo, acessível em pequena escala, que não exige mão de obra especializada, requer poucos equipamentos, libera poucos odores desagradáveis, não atrai insetos devido ao uso de ácido, e cujo $\mathrm{pH}$ baixo diminui a presença de patógenos. A adição de carboidratos no processo de ensilagem de peixe, segundo Benites e SouzaSoares (2010), otimiza a secagem e proporciona ganhos em qualidade nutricional dependendo de sua digestibilidade e características físicoquímicas. Com isso, a utilização de fontes energéticas de subprodutos agrícolas, como a farinha de algaroba (Prosopis juliflora (Sw.) DC), a casca e a farinha de varredura de mandioca (Manihot esculenta) e o farelo de milho, adicionados ao resíduo de peixe no processo de ensilagem, pode ser viável para elaboração de um produto para a alimentação de frangos de corte.
A produção de tilápia no Brasil, entre os anos de 2007 e 2013, praticamente triplicou, passando de 95 a 250 mil toneladas. No ano de 2013, a produção correspondeu a $12,5 \%$ de toda a produção de pescado nacional (Anuário..., 2013/14), sendo o peixe mais cultivado no país. $\mathrm{Na}$ filetagem da tilápia em condições industriais, cerca de dois terços em peso são descartados como subproduto (Rocha et al., 2013). Assim, na atualidade, a estimativa é que anualmente são geradas 167 mil toneladas de resíduo agroindustrial com a filetagem da tilápia, representando um importante passivo ambiental se não for racionalmente aproveitado.

Objetivou-se com este trabalho avaliar o valor nutricional e energético de diferentes farinhas mistas produzidas com silagem contendo resíduo de filetagem de tilápia e diferentes fontes de carboidratos para frangos de corte.

\section{MATERIAL E MÉTODOS}

O experimento foi desenvolvido no setor de avicultura da Universidade Federal Rural de Pernambuco (UFRPE), aprovado pelo Comitê de Ética e Biossegurança da UFRPE, por meio do Protocolo $\mathrm{n}^{\mathrm{o}}$ 23082.010815/2012, licença $053 / 2012$. As farinhas mistas contendo silagem de peixe foram elaboradas e desidratadas no Departamento de Zootecnia da UFRPE. Os resíduos da filetagem de tilápia, selecionados e utilizados para confecção da silagem acidificada e posterior obtenção das farinhas mistas, foram moídos em processador de resíduos orgânicos e acrescidos de vinagre comercial, com o objetivo de acidificar o meio promovendo hidrólise das proteínas do peixe, o abaixamento do $\mathrm{pH}$ e a inibição da proliferação de patógenos. Posteriormente foi acrescentada uma fonte de carboidrato fermentável (o farelo de algaroba, a farinha de varredura de mandioca, o farelo de milho ou o farelo de casca de mandioca) para aumentar a qualidade energética da silagem, diminuir a umidade e facilitar a secagem do material. A proporção utilizada na confecção dos 
quatro tipos de silagens foi $60 \%$ de resíduo da filetagem de tilápia, $6 \%$ de vinagre e $34 \%$ de fonte de carboidrato.

As silagens mistas foram mantidas durante um mês, em recipientes hermeticamente fechados, até a estabilização e, em seguida, foram desidratadas ao sol e trituradas, para obtenção dos quatro tipos de farinhas mistas de silagem de peixe: com farelo de algaroba (SFA), com a farinha de varredura de mandioca (SFVM), com o farelo de milho (SFM) e com a casca de mandioca (SCM). Ao final do processo, foi adicionado um agente antioxidante (BHT) às farinhas mistas para inibir a continuidade dos processos de oxidação. No Laboratório de Química dos Solos do Departamento de Agronomia da UFRPE, foi realizada a determinação dos valores de matéria seca (MS), proteína bruta $(\mathrm{PB})$, fibra bruta $(\mathrm{FB})$, extrato etéreo $(\mathrm{EE})$ e matéria mineral $(\mathrm{MM})$ das farinhas mistas e o potencial hidrogeniônico $(\mathrm{pH})$ das silagens e farinhas mistas, de acordo com metodologias descritas por Silva e Queiroz (2002). As análises de cálcio (Ca), fósforo $(\mathrm{P})$ e energia bruta (EB) das farinhas mistas foram realizadas no Instituto Tecnológico de Pernambuco (ITEP), de acordo com a metodologia reportada por Silva e Queiroz (2002).

Um ensaio de digestibilidade com frangos de corte da linhagem Vermelho Pesadão Francês de 28 a 38 dias de idade foi realizado por meio do método de coleta total de excretas, para obtenção dos valores de energia metabolizável aparente (EMA) e EMA corrigida para nitrogênio (EMAn) das quatro farinhas mistas elaboradas. Foram utilizadas 30 gaiolas metabólicas, com dimensões de $1,00 \times 0,50 \times 0,50 \mathrm{~m}$, para alojar 180 frangos de corte da linhagem Pesadão. As aves receberam água e ração à vontade, em bebedouro tipo "nipple" e comedouro tipo calha, além de iluminação artificial por $24 \mathrm{~h}$. O delineamento adotado foi o inteiramente ao acaso, com cinco tratamentos, seis repetições e seis aves por unidade experimental. Os tratamentos consistiram de uma ração referência (RR) e quatro rações-teste, compostas de $70 \%$ da RR e $30 \%$ de uma das quatro farinhas mistas (na matéria natural). A RR foi formulada para atender a exigência nutricional de frangos de corte de desempenho regular (Tab. 1) de acordo com Rostagno et al. (2011). As aves começaram a receber a ração experimental aos 28 dias de idade, e o período experimental foi de 10 dias, sendo cinco de adaptação dos animais às dietas e cinco de coleta total de excretas. As rações fornecidas foram pesadas, e as sobras mensuradas para obtenção do consumo. Para determinar visualmente o início e o final da coleta, foi adicionado às rações, respectivamente, no início e final do período de coleta, $1,5 \%$ de óxido férrico.

Tabela 1. Composição percentual calculada da ração referência na base matéria natural

\begin{tabular}{lc}
\hline Ingrediente & Quantidade (\%) \\
\hline Milho grão moído & 62,56 \\
Farelo de soja & 31,06 \\
Farelo de trigo & 1,20 \\
Óleo de soja & 2,10 \\
Fosfato bicálcico & 1,13 \\
Calcário calcítico & 0,87 \\
Sal comum & 0,43 \\
DL-metionina 99\% & 0,21 \\
L-lisina 78,8\% & 0,14 \\
L-treonina 98\% & 0,009 \\
Cloreto colina & 0,10 \\
Suplemento vitaminico & 0,10 \\
Suplemento mineral ${ }^{2}$ & 0,08 \\
\hline Composição calculada & \\
\hline EM (kcal/kg) & 2980 \\
Proteína bruta (\%) & 20,00 \\
Fosforo disponível (\%) & 0,37 \\
Cálcio (\%) & 0,79 \\
Sódio (\%) & 0,20 \\
Aminoácidos digestíveis & \\
Metionina + cistina & 0,81 \\
Lisina & 1,12 \\
Treonina & 0,73 \\
Triptofano & 0,22 \\
\hline 1-Concentraca por & $v i t a n g$
\end{tabular}

1-Concentração por $\mathrm{kg}$ do produto: vitamina $\mathrm{A}$ 7.500.000UI, vitamina D3 2.500.000UI, vitamina E $18.000 \mathrm{UI}$, vitamina $\mathrm{K} 31.200 \mathrm{mg}$, tiamina $1.500 \mathrm{mg}$, riboflavina $5.500 \mathrm{mg}$, piridoxina $2.000 \mathrm{mg}$, vitamina B12 $12.500 \mu \mathrm{g}$, niacina $35 \mathrm{~g}$, pantotenato de cálcio $10 \mathrm{~g}$, biotina $67 \mathrm{mg}$. 2-concentração por kg do produto: ferro $60 \mathrm{~g}$, cobre $13 \mathrm{~g}$, manganês $120 \mathrm{~g}$, zinco $100 \mathrm{~g}$, iodo $2.500 \mathrm{mg}$, selênio $500 \mathrm{mg}$.

Para a coleta total de excretas, foram utilizadas bandejas forradas com lona plástica preta sob o piso de cada gaiola. O material coletado foi pesado e acondicionado em sacos plásticos, devidamente identificados e armazenados em freezer a $-20^{\circ} \mathrm{C}$. Posteriormente, o material foi descongelado, homogeneizado por unidade 
experimental, e separou-se uma alíquota de $20 \%$ para pré-secagem em estufa a $55^{\circ} \mathrm{C}$ por 72 horas. Após as excretas, as rações experimentais foram moídas, obtendo-se uma amostra para análises laboratoriais de MS, PB, EB, EE e MM, segundo as metodologias descritas por Silva e Queiroz (2002). Com base nesses resultados, foram calculados os coeficientes de metabolização aparente da matéria seca (CMAMS), proteína bruta (CMAPB) e energia bruta (CMAEB). Também se fundamentando nas fórmulas propostas por Matterson et al. (1965), foram calculados os valores de EMA e EMAn das farinhas mistas contendo silagem de peixe.

Os resultados foram submetidos à análise de variância pelo programa estatístico Assistat 7.5
(Silva e Azevedo, 2006), e as médias comparadas pelo teste de Tukey $(\mathrm{P}<0,05)$.

\section{RESULTADOS E DISCUSSÃO}

Os resultados obtidos para a avaliação nutricional das diferentes farinhas mistas de silagem de peixe estão apresentados na Tab. 2. A farinha mista produzida com o farelo de milho foi a que apresentou os maiores valores para a PB $(21,99 \%)$ quando comparada com as demais silagens. A farinha mista confeccionada com a farinha de varredura obteve os maiores valores para EE $(23,22 \%)$ e EB $(4862 \mathrm{kcal} / \mathrm{kg})$. Com isso, o alto conteúdo de $\mathrm{EE}(23,22 \%)$ encontrado na SFVM pode ter influenciado no valor de EB dessa farinha.

Tabela 2. Avaliação nutricional das farinhas mistas de silagem de peixe contendo farelo de algaroba (SFA), farinha de varredura de mandioca (SFVM), farelo de milho (SFM) e casca de mandioca (SCM)*

\begin{tabular}{lcccc} 
Variável & SFA & SFVM & SFM & SCM \\
\hline Matéria seca, \% & 85,81 & 85,14 & 87,57 & 90,79 \\
Proteína bruta, \% & 20,63 & 20,76 & 21,99 & 14,54 \\
Extrato etéreo, \% & 17,04 & 23,22 & 21,97 & 20,27 \\
Matéria mineral, \% & 7,53 & 7,79 & 8,65 & 8,83 \\
Fibra bruta, \% & 23,07 & 10,55 & 16,81 & 12,34 \\
Energia bruta, kcal/kg & 4615 & 4862 & 4765 & 4447 \\
Cálcio,\% & 1,79 & 2,30 & 1,57 & 2,72 \\
Fósforo,\% & 1,12 & 1,72 & 1,45 & 1,94 \\
Densidade,g/L** & 532 & 528 & 598 & 508 \\
pH** & 4,5 & 4,0 & 4,4 & 4,4 \\
\hline
\end{tabular}

*Valores expressos em base de matéria seca; ${ }^{* *}$ valores expressos na base natural.

A farinha mista produzida com as cascas da mandioca obteve os menores valores para $\mathrm{PB}$ $(14,54 \%)$ e EB $(4447 \mathrm{kcal} / \mathrm{kg})$. A farinha mista elaborada com o farelo de algaroba apresentou o maior nível de FB (23,07\%). Isso é justificado pelo fato de o farelo de algaroba usado nessa farinha mista ser parcialmente composto pelas cascas da algaroba.

O valor nutritivo da farinha mista pode ser alterado de acordo com o grau de frescor do resíduo de peixe e suas condições de armazenamento antes do processo de ensilagem. Os minerais analisados foram $\mathrm{Ca}$ e $\mathrm{P}$, sendo possível observar uma pequena variação nos teores desses minerais nas farinhas mista. Isso pode ser explicado não só pelas diferentes fontes de carboidratos utilizadas como também pela qualidade dos resíduos utilizados. Os resíduos de tilápia foram compostos por cabeça, vísceras, pele, esqueleto, escamas e restos musculares.
Segundo Santos (2000), a proporção dos minerais nessas partes pode influenciar no teor destes no produto final, visto que a sua distribuição ocorre em diferentes partes do corpo do animal, como o cálcio e o fósforo, que se acumulam principalmente no esqueleto e nas escamas, enquanto as vísceras e a pele possuem taxas menores. Goddard e Perret (2005), ao trabalharem com silagem ácida de sardinha indiana cossecas com farelo de trigo, obtiveram valores de $48-58 \%$ de $\mathrm{PB}, 36-51 \%$ de umidade, 14- $17 \%$ de MM e 7,5-8,6\% de EE. Os valores de PB e MM das quatro farinhas mistas produzidas foram inferiores aos encontrados por Benites e Souza-Soares (2010), que trabalharam com silagens de pescada e castanha cossecas com o farelo de arroz em $30 \%$ e acidificadas com vinagre. Aqueles autores obtiveram 31-31,7\% de PB e 25,6-26,8\% de MM. Porém, os valores de EE nas farinhas mistas foram superiores aos reportados por aqueles autores, que encontraram 


\section{Cunha et al.}

uma variação de $15,4 \%$ a $19,2 \%$. Os teores de EE e EB das quatro farinhas mistas confeccionadas foram superiores aos encontrados por Oliveira (2006), que obteve para a silagem ácida de resíduos de tilápia sem a adição de carboidratos $19,25 \%$ de EE e $3911 \mathrm{kcal} / \mathrm{kg}$ de EB, evidenciando os ganhos em energia quando se adicionam carboidratos no processo. Santos (2000), ao trabalhar com silagem de resíduos de pescado de águas marinhas e com $30 \%$ de farinha de trigo armazenados por 30 dias, obteve um valor semelhante de PB $(21,57 \%)$ aos quatro tipos de silagens estudadas, um valor inferior de EE $(5,04 \%)$ e um valor superior de MM $(13,65 \%)$. O autor observou que o pH após o processo de secagem manteve-se em 4,1, valor similar ao $\mathrm{pH}$ das silagens utilizadas nesta pesquisa.

No final do período de fermentação, a avaliação do $\mathrm{pH}$ da silagem foi de 5,3 para a SFA, 5,2 para a SFVM, 5,5 para a SFM e 5,3 para a SCM. Após a secagem, o pH das farinhas mistas se estabilizou em 4,5 na SFA, 4,0 na SFVM, 4,4 na SFM e 4,4 na SCM. Assim como observado por Santos (2000), verificou-se uma estabilidade microbiológica das silagens principalmente pelo fato de os carboidratos incorporados ao processo possuírem um alto teor de matéria seca. Nos produtos pesqueiros ensilados, deve ser considerada a ação bacteriostática da acidez, que proporciona maior segurança a esse tipo de produto.

$\mathrm{Na}$ Tab. 3, estão apresentados os coeficientes de metabolização aparente e os valores de EMA e EMAn das quatro farinhas mistas avaliadas. O CMAMS teve o menor valor para a SFA e, para as demais farinhas mistas, não foram verificadas diferenças significativas por meio do teste de comparação de médias.

Tabela 3. Coeficientes de metabolizabilidade aparente da matéria seca (CMAMS), proteína bruta (CMAPB) e energia bruta (CMAEB) e os valores de energia metabolizável aparente (EMA) e corrigida para balanço de nitrogênio (EMAn) da ração referência (RR) e das farinhas mistas de peixe com farelo de algaroba (SFA), farinha de varredura de mandioca (SFVM), farelo de milho (SFM) e casca de mandioca $(\mathrm{SCM})^{*}$

\begin{tabular}{lccccccc}
\hline Variável & $\begin{array}{c}\text { Ração } \\
\text { referência }\end{array}$ & SFA & SFVM & SFM & SCM & CV\% & P \\
\hline CMAMS (\%) & 74,50 & $65,22^{\mathrm{b}}$ & $70,08^{\mathrm{a}}$ & $70,23^{\mathrm{a}}$ & $71,47^{\mathrm{a}}$ & 2,06 & 0,01 \\
CMAPB (\%) & 57,84 & $47,56^{\mathrm{b}}$ & $52,00^{\mathrm{a}}$ & $46,20^{\mathrm{b}}$ & $53,22^{\mathrm{a}}$ & 3,59 & 0,01 \\
CMAEB (\%) & 77,12 & $69,48^{\mathrm{b}}$ & $75,37^{\mathrm{a}}$ & $74,87^{\mathrm{a}}$ & $76,56^{\mathrm{a}}$ & 1,69 & 0,01 \\
EMA, kcal/kg & 3564 & $3560^{\mathrm{c}}$ & $3574^{\mathrm{a}}$ & $3570^{\mathrm{b}}$ & $3571^{\mathrm{ab}}$ & 0,06 & 0,01 \\
EMAn, kcal/kg & 3405 & $3402^{\mathrm{b}}$ & $3415^{\mathrm{a}}$ & $3412^{\mathrm{a}}$ & $3413^{\mathrm{a}}$ & 0,06 & 0,01 \\
\hline
\end{tabular}

Valores expressos em base de matéria seca*; CV- coeficiente de variação; a,b,c. Médias seguidas de letras diferentes na linha diferem estatisticamente pelo teste de Tukey.

Os piores valores obtidos de CMAPB foram para a SFA e a SFM. A SFA obteve o menor valor para o CMAEB quando comparada com as demais farinhas mistas. Provavelmente por este ingrediente conter um alto teor de FB $(23,07 \%)$, isso tenha refletido no conteúdo energético. Silva et al. (2009), ao trabalharem com frangos de corte de crescimento lento, analisaram a composição físico-química dos farelos de resíduo de tomate e de goiaba, encontrando valores de 55,62 e 43,66\% de FB (na matéria natural), respectivamente, em rações contendo $70 \%$ de ração-referência e 30\% dos farelos citados. Esse resultado justifica $o$ fato de que os altos percentuais de FB possivelmente refletem no conteúdo energético dos farelos, provocando diluição na EMA, uma vez que, no trato digestório desses animais, não há secreção endógena de enzimas que atuam sobre as ligações $\beta$ presentes nos polissacarídeos contidos na fração fibrosa, além de baixa atividade cecal. As farinhas mistas de SFVM, SFM e a SCM proporcionaram os maiores valores de CMAEB, provavelmente pelo maior teor de EE, pela presença de maior quantidade de amido e menor quantidade de FB $(10,55 \%), \quad(16,81 \%)$ e $(12,34 \%)$, respectivamente, quando comparadas com a SFA $(23,07 \%)$ de FB.

Os valores de EMA e EMAn determinados das quatro farinhas mistas confeccionadas diferiram estatisticamente entre si $(\mathrm{P}<0,01)$, variaram de 3560 a $3574 \mathrm{kcal} / \mathrm{kg}$ para a EMA e de 3402 a $3415 \mathrm{kcal} / \mathrm{kg}$ para a EMAn, respectivamente. 
Oliveira (2012), ao trabalhar com frangos de corte de 14 a 25 dias de idade, fornecendo as quatro farinhas mistas citadas no presente trabalho, porém com $40 \%$ no nível de inclusão, não observou diferença estatística entre os valores de EMA ou EMAn das farinhas mistas, que variaram de 3804 a $3842 \mathrm{kcal} / \mathrm{kg}$ para a EMA e de 3563 a $3600 \mathrm{kcal} / \mathrm{kg}$ para a EMAn.

Vários fatores afetam os valores de energia metabolizável, entre os quais a idade das aves, o alimento, a composição química, o nível de inclusão do ingrediente teste, a taxa de consumo, a metodologia utilizada para determinação dos valores energéticos e os fatores antinutricionais dos alimentos (Soares et al., 2005). Kjos et al. (2000) encontraram, para a EMA de silagens de salmão preservada pela adição de ácido fórmico para frangos de corte na fase inicial, valores de $2746 \mathrm{kcal} / \mathrm{kg}$ e $2703 \mathrm{kcal} / \mathrm{kg}$ em rações contendo esse tipo de silagem de peixe com níveis de $5 \%$ e $10 \%$ da dieta, respectivamente.

A avaliação da digestibilidade de farinhas de silagem de peixe principalmente com a adição de carboidratos ainda é escassa. Contudo, o estudo demonstrou que a inclusão de carboidratos fermentáveis favorece a queda de $\mathrm{pH}$, possibilitando uma melhor fermentação, e, ao mesmo tempo, ocasionou o aumento do teor energético do produto final. Os valores nutricionais dos ingredientes foram satisfatórios para utilização em dietas para frangos de corte, diminuindo, assim, os custos de produção e a poluição ambiental.

\section{CONCLUSÕES}

Os valores nutricionais das farinhas mistas contendo silagem de peixes para frangos de corte da linhagem Pesadão foram favoráveis quando consideradas a EMA e a EMAn, que variaram de 3560 a $3574 \mathrm{kcal} / \mathrm{kg}$ e de $3402 \mathrm{kcal} / \mathrm{kg}$ a $3415 \mathrm{kcal} / \mathrm{kg}$, respectivamente. Entre os ingredientes avaliados, as farinhas mistas contendo silagem de peixes e a farinha de varredura de mandioca (SFVM) ou a de casca da mandioca (SCM) foram as que apresentaram melhores resultados de coeficiente de metabolizabilidade da proteína, de $52,00 \%$ e $53,22 \%$, e da energia, de $75,37 \%$ e $76,56 \%$, respectivamente.

\section{REFERÊNCIAS}

ANUÁRIO BRASILEIRO DE PESCA E AQUICULTURA. Santa Catarina: ACEB, v.1, p.133, 2013-2014.

BENITES, C.I.; SOUZA-SOARES, L.A. Farinhas de silagem de resíduo de pescado cosecas com farelo de arroz: uma alternativa viável. Arch. Zootec., v.59, p.447-450, 2010.

BORGHESI, R. Avaliação fisico-química $e$ biológica das silagens ácida, biológica e enzimática elaboradas com descarte e resíduo do beneficiamento da tilápia do Nilo (Oreochromis niloticus). 2004. 108f. Dissertação (Mestrado em Ciência e Tecnologia de Alimentos) - Escola Superior de Agricultura "Luiz de Queiroz", Universidade de São Paulo, Piracicaba, SP.

BRUM JR., B.S.; ZANELLA, I.; TOLEDO, G.S.P. et al. Dietas para frangos de corte contendo quirera de arroz. Cienc. Rural, v.37, p.1423-1429, 2007.

GODDARD, J.S.; PERRET, J.S.M. Co-drying fish silage for use in aquafeeds. Anim. Feed Sci. Technol., v.118, p.337-342, 2005.

KJOS, N.P.; HERSTAD, O.; OVERLAND, M. et al. Effects of dietary fish silage and fish fat on growth performance and meat quality of broiler chicks. Can. J. Anim. Sci., v.80, p.625-632, 2000.

MATTERSON, L.D.; POTTER, L.M.; STUTZ, M.W. The metabolizable energy of feed ingredients for chickens. Agricult. Exp. Station Res. Rep., v.7, p.3-11, 1965.

OLIVEIRA, C.R.C. Avaliação nutricional de farinhas de silagem de peixe em dietas para frangos de corte. 2012. 82f. Dissertação (Mestrado em Zootecnia) - Departamento de Zootecnia, Universidade Federal Rural de Pernambuco, PR.

OLIVEIRA, M.M.; PIMENTA, M.E.S.G.; CAMARGO, A.C.S. et al. Silagem de resíduos da filetagem de tilápia do Nilo (Oreochromis niloticus), com ácido fórmico - análise bromatológica, físico-química e microbiológica. Ciênc. Agrotec., v.30, p.1218-1223, 2006.

RICHART, E.; NUNES, R.V.; CASTILHA, L.D. et al. Nutritional evaluation of tilapia filleting waste meal for swine in the nursery phase. Rev. Caatinga, v.29, p.473-480, 2016. 


\section{Cunha et al.}

ROCHA, C.M.C.; RESENDE, E.K.; ROUTLEDGE, E.A.B. et al. Avanços na pesquisa e no desenvolvimento da aquicultura brasileira. Pesqui. Agropecu. Bras., v.48, p.iv-vi, 2013. (prefácio).

ROSTAGNO, H.S.; ALBINO, L.F.T.; DONZELE, J.L. et al. Tabelas brasileiras para aves e suínos: composição de alimentos e exigências nutricionais. 3.ed. Viçosa: UFV, 2011. 252p.

SANTOS, N.F. Processamento, caracterização química e nutricional da silagem biológica de resíduos de pescado para uso em alimentação animal. 2000. 84f. Dissertação (Mestrado em Ciência e Tecnologia de Alimentos) Departamento de Tecnologia de Alimentos, Universidade Federal do Ceará, Fortaleza, CE.
SILVA, D.J.; QUEIROZ, A.C. Análise de alimentos: métodos químicos e biológicos. 7.ed. Viçosa: UFV, 2002. 235p.

SILVA, E.P.; SILVA, D.A.T.; RABELLO, C.B.V. et al. Composição físico-química e valores energéticos dos resíduos de goiaba e tomate para frangos de corte. Rev. Bras. Zootec., v.38, p.1051-1058, 2009.

SILVA, F.A.S.; AZEVEDO, C.A.V. A new version of the Assistat-computers in agriculture. In: WORLD CONGRESS CONFERENCE, PROCEEDINGS, 4., 2006, Orlando. Proceedings... Orlando: [s.n], 2006. p.393-396. (Resumo).

SOARES, K.R.; BERTECHINI, A.G.; FASSANI, E.J. et al. Valores de energia metabolizável de alimentos para pintos de corte na fase pré-inicial. Ciênc. Agrotec., v.29, p.238244, 2005. 